\title{
PREVALENCE OF INDUCIBLE CLINDAMYCIN RESISTANCE IN CLINICAL ISOLATES OF METHICILLIN-RESISTANT STAPHYLOCOCCUS AUREUS MEDIATED THROUGH GENE ERMC EXPRESSION
}

\author{
NIMISHA TANDON ${ }^{1,2}$, MADHURI KULKARNI ${ }^{1}$, SOWMYA GS ${ }^{1}$, FAUZIA TABASSUM ${ }^{3}$, MD SAYEED AKHTAR ${ }^{2,4 *}$ \\ ${ }^{1}$ Department of Microbiology, JSS Medical college, Mysuru - 570 015, Karnataka, India. ${ }^{2}$ Department of Microbiology, School of Allied \\ Health Sciences, Sharda University, Knowledge Park-III, Greater Noida - 201 306, Uttar Pradesh, India. ${ }^{3}$ Department of Pharmacology, All \\ India Institute of Medical Sciences, Patna, Bihar, India. ${ }^{4}$ Department of Clinical Pharmacy, College of Medicine and Health Sciences, Ambo \\ University, Ambo-19, Ethiopia. Email: sayeedpp@gmail.com \\ Received: 14 March 2018, Revised and Accepted: 12 May 2018
}

ABSTRACT

Objective: The objective of this study is to determine the phenotypic and genotypic expression of inducible clindamycin resistance due to the expression of ermA, ermB, and erm C genes in clinical isolates of methicillin-resistant Staphylococcus aureus (MRSA) by double disc diffusion and uniplex PCR.

Method: This cross-sectional study was conducted in microbiology department of an university teaching hospital. A total of 604 non-duplicate clinical isolates of S. aureus evaluated for MRSA and were subjected to uniplex PCR for ermA, ermB, and ermC genes, respectively.

Result: The analysis of 604 isolates showed that 220 (36.42\%) were of MRSA. Out of which, 69 (11.42\%) were demonstrated as inducible clindamycin resistance by double-disc diffusion method, and among inducible resistant isolates, 25 isolates of ermC (84\%) were positive and $4(16 \%)$ were negative, whereas, ermA and ermB genes could not be demonstrated by the genotypic method.

Conclusion: We observed that clindamycin may serve as a good alternative and advocated in severe MRSA infection based on susceptibility pattern. We observed D test as a mandatory method to detect inducible clindamycin Staphylococcus. Importantly, ermC gene is a major determinant of resistance to macrolides among MRSA.

Keywords: methicillin-resistant Staphylococcus aureus, Erm genes, D-test, Macrolide lincosamide streptograminB.

(C) 2018 The Authors. Published by Innovare Academic Sciences Pvt Ltd. This is an open accessarticle under the CC BY license (http://creativecommons. org/licenses/by/4. 0/) DOI: http://dx.doi.org/10.22159/ajpcr.2018.v11i9.25928

\section{INTRODUCTION}

Staphylococci are Gram-positive cocci that occur in grape-like clusters [1]. Methicillin-resistant Staphylococcus aureus (MRSA) is a potent pathogenic organism that causes nosocomial as well as community-acquired infections with both endemic and epidemic spread [2]. Worldwide, there is a considerable increased prevalence of MRSA which was observed in last decade [3]. In India, MRSA prevalence rate ranges from $30 \%$ to $80 \%$ among all S. aureus infections [4]. MRSArelated death estimated to be $64 \%$ more likely in comparison to others. The increased cost of health care in low-income countries occurred due to increased hospitalization and this call for intensive care of the patient [5]. The cost of treating MRSA infections is four-fold more than its sensitive counterparts [6,7]. The strict surveillance and appropriate prevention measures during management of MRSA infections reduce the prevalence, rate of mortality, and treatment expenditure [8,9].

Clindamycin, a macrolide lincosamide streptogramin $\mathrm{B}\left(\mathrm{MLS}_{\mathrm{B}}\right)$ type of antibiotic is useful for penicillin-allergic cases for the treatment of skin and soft tissue infections of $S$. aureus $[3,10]$. Clindamycin is quite a good alternative and used as both parenteral and oral use and has good tissue distribution along with potent bacteriostatic action against S. aureus [11]. The therapeutic failure of clindamycin occurs due to lack of inducible clindamycin resistance [12,13]. Staphylococci labeling as clindamycin resistant could stop prescription of Clindamycin even it is only erythromycin resistant and susceptible to clindamycin [12,14].

$\mathrm{MLS}_{\mathrm{B}}$ is presented as either constitutive (MLSB ${ }_{C}$ phenotype) or inducible (MLSB ${ }_{1}$ phenotype) due to enzyme encoded by a variety of erm genes. Alternatively, the resistance is mediated through active efflux pump encoded by msrA gene called MS phenotype [3]. ErmA, ermB, and ermC develop the resistance to MLS type $B\left(M_{B}\right)$ by altering target site of the ribosome [15].

The use of in vitro susceptibility test for the identification of resistance to erythromycin in converse to clindamycin sensitivity by D test is a need of time [3].

The prevalence of inducible clindamycin resistance varies in the different geographical region. Therefore, keeping these facts in mind, the present study was conducted to detect the prevalence of inducible clindamycin resistance by D-test and to investigate the presence of macrolide resistance along with the detection of ermA, ermB, and ermC genes in clinical isolates of $S$. aureus.

\section{MATERIALS AND METHODS}

This prospective study was conducted for 12 months from March 2014 to February 2015. A total of 604 non-duplicate clinical isolates were taken from various specimens such as pus, swab, and blood. All the samples were tested for its susceptibility by disc diffusion method (CLSI, 2007). All clinical isolates of MRSA during the study period were included. In contrast, all the specimens having mecA gene-negative isolates are excluded from the study.

\section{Phenotypic method}

For the detection of MRSA and inducible clindamycin resistance, samples were processed by standard microbiological methods and S. aureus was identified by standard laboratory procedures. The isolates were further characterised by oxacillin screen agar and cefoxitin disc diffusion to 
identify it as MRSA. Lack of a D-shaped zone in erythromycin-resistant and clindamycin-susceptible isolates was interpreted as $\mathrm{M} / \mathrm{MS}_{\mathrm{B}}$ efflux phenotype.

\section{Genotypic method}

For the extraction of DNA, two-step lysostaphin and phenol-chloroform method was used as described by Anand et al. in 2009. The prepared pellets of MRSA isolates were dissolved in $50 \mu \mathrm{l}$ of sterile water and DNA was stored at $-20^{\circ} \mathrm{C}$.

Detection of mecA and ermA, $B$, and $C$ genes

Selected strains were subcultured on the top of blood agar and incubated overnight at $35{ }^{\circ} \mathrm{C}$. Bacterial DNA was extracted by phenolchloroform protocol, and uniplex PCR was carried out using specific primers for the detection of mecA and ermA, B, and C genes.

Amplification of mecA, and ermA, B, and $C$ genes using 1 primer/uniplex PCR method

Primers used for ermA, B, and C were procured from Sigma-Aldrich, Missouri, United States.

\section{Preparation of PCR mix for mecA gene detection}

Preparation of PCR master mix for $25 \mu \mathrm{l}$ was done by taking $2.5 \mu \mathrm{l}$ of $\times 10$ Dream Taq Buffer (Thermo Fischer Scientific, California, USA) containing $25 \mathrm{mM} \mathrm{MgCl} 2.5 \mu \mathrm{l}$ of dNTPs containing all the 4 dNTPs at 2 $\mathrm{mM}$ concentration and $0.125 \mu \mathrm{l}$ of Taq polymerase ( 5 units/ $\mu \mathrm{l}) .2 \mu \mathrm{l}$ of DNA and $0.1 \mu \mathrm{l}$ each of forward and reverse primers of mecA gene $(100$ $\mu \mathrm{M}$ ) and $18.875 \mu \mathrm{l}$ of sterile water.

Preparation of PCR mix for ermA, $B$, and C by uniplex PCR

Preparation of PCR master mix for $25 \mu \mathrm{l}$ was done by making $2.5 \mu \mathrm{l}$ of $\times 10$ Dream Taq Buffer containing $25 \mathrm{mM} \mathrm{MgCl}_{2}$ (Thermo Fisher Scientific, California, USA).

Optimal cycling conditions for the PCR amplifications of ermA, $B$, and $C$ genes

Biorad PCR equipment was used for PCR amplification. PCR master mix was dispensed in $200 \mu \mathrm{l} \mathrm{PCR}$ tubes. The optimal cycling conditions for ermA and $\mathrm{C}$ genes were as follows: $93^{\circ} \mathrm{C}$ for $3 \mathrm{~min}, 35$ cycles of $93^{\circ} \mathrm{C}$ for $1 \mathrm{~min}, 37^{\circ} \mathrm{C}$ for $1 \mathrm{~min}$, and $72^{\circ} \mathrm{C}$ for $1 \mathrm{~min}$, followed by a final extension of $72^{\circ} \mathrm{C}$ for $7 \mathrm{~min}$, whereas, for ermB gene, the annealing temperature was at $42^{\circ} \mathrm{C}$ for $1 \mathrm{~min}$

\section{Gel electrophoresis}

Gel electrophoresis was done to separate amplicons, and detection of separated amplicons was done under UV light. Gene Ruler-1kb DNA ladder was used as the marker (Thermo Fischer Scientific, California, USA).

\section{RESULT}

The majority of the MRSA isolates were collected from the surgery department $(21.68 \%)$, followed by ICU $(11.75 \%)$ and orthopedics (7.45\%) comprising $40.88 \%$ of the total isolates (Fig. 1).

The most common clinical conditions associated with MRSA were skin and soft tissue infections that account $29.77 \%$. Among this, the majority were an abscess $(13.9 \%)$ from different surgical site infection such as carbuncle, furuncle, and pyoderma. Bone infections and respiratory infections were comparatively rare (2\%) (Table 1 ).

The antibiotic pattern for MRSA is shown in Fig. 2a and inducible clindamycin resistance can be depicted by the D-test which is shown in Fig. 2b.

As shown in Fig. 3, isolates 1, 5, 9, 15, 20, and 22 are not grown on oxacillin-resistant screen agar (ORSA).
The ORSA is used to differentiate between MRSA and methicillinsensitive Staphylococcus aureus (MSSA). The presence of amplified mecA gene is significant for the detection of MRSA genotypically which is shown in Lane 2-15 (Fig. 4).

According to sample distribution for MRSA, pus is the most common specimen followed by an abscess, blood, urine, ear swab, pleural fluid, sputum, endotracheal tube, ENT, catheter tip, and others (Table 2). Of which, 69 were demonstrated as inducible clindamycin resistance by D-test (11.42\%) (Table 2)

Among ermA, ermB, and erm $\mathrm{C}$ genes by $\mathrm{PCR}$, erm $\mathrm{C}$ is the predominant genetic determinant for the expression of resistance to macrolides among MRSA 21 (84\%) (Figs. 5 and 6).

Table 1: Clinical conditions associated with MRSA

\begin{tabular}{lll}
\hline S. No. & Clinical Conditions & Total Isolates (\%) \\
\hline 1. & Abscess & $84(13.9)$ \\
2. & Skin infection & $63(10.43)$ \\
3. & Others & $37(6.12)$ \\
4. & Ear infection & $25(4.13)$ \\
5. & Bone and joint infections & $13(2.15)$ \\
6. & Wound infection & $12(1.98)$ \\
7. & Respiratory infection & $10(1.65)$ \\
8. & Ulcer & $10(1.65)$ \\
9. & Diabetic foot & $6(0.99)$ \\
10. & Surgical site infection & $3(0.49)$ \\
11. & Gangrene & $3(0.49)$ \\
12. & Necrotizing fasciitis & $2(0.33)$ \\
13. & Urinary tract infection & 0 \\
14. & Bacteremia & 0 \\
15. & Diagnosis not known & $336(55.62)$ \\
\hline
\end{tabular}

MRSA: Methicillin-resistant Staphylococcus aureus

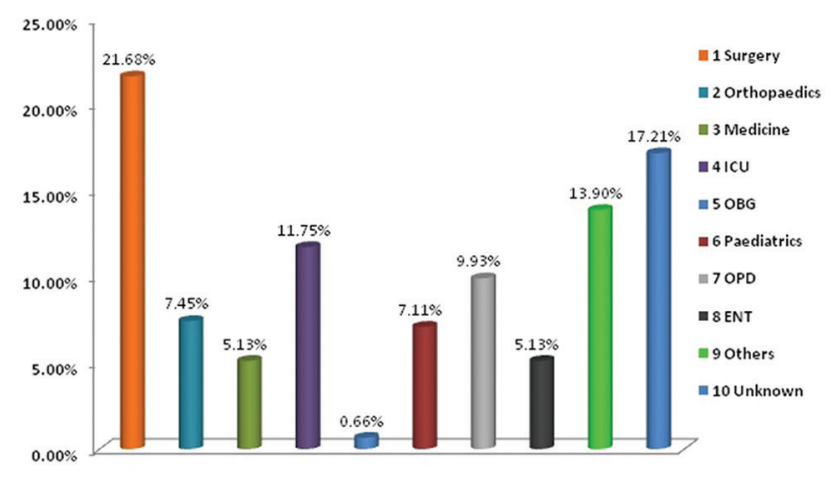

Fig. 1: Methicillin-resistant Staphylococcus aureus isolated pattern from different department of the hospital

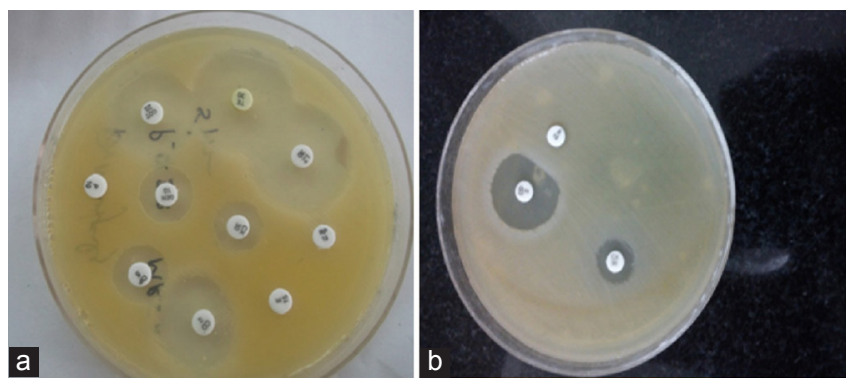

Fig. 2: (a) Antimicrobial susceptibility pattern of methicillinresistant Staphylococcus aureus (b) cefoxitin resistance and D- test positive for clindamycin 
Table 2: Sample-wise distribution of the $S$. aureus, MRSA isolates having inducible clindamycin resistance

\begin{tabular}{lllll}
\hline Samples & S. aureus (\%) & MRSA (\%) & MRSA+IR Genotype (\%) & MRSA+IR Phenotype (\%) \\
\hline Pus & $442(73.17)$ & $163(26.98)$ & $17(68)$ & $58(9.6)$ \\
Abscess & $44(7.28)$ & $17(2.81)$ & $01(4)$ & $02(0.33)$ \\
Blood & $24(3.97)$ & $10(1.65)$ & 00 & $01(0.16)$ \\
Urine & $09(1.47)$ & $06(0.99)$ & 00 & 0 \\
Ear swab & $26(4.3)$ & $07(1.15)$ & $01(4)$ & $01(0.16)$ \\
Pleural fluid & $09(1.49)$ & $01(0.16)$ & 00 & 0 \\
Sputum & $16(2.64)$ & $08(1.32)$ & $01(4)$ & $02(0.33)$ \\
ET & $28(4.63)$ & $01(0.16)$ & $01(4)$ & $03(0.49)$ \\
ENT & $01(0.16)$ & $03(0.49)$ & 00 & $01(0.16)$ \\
CT & $04(0.66)$ & $03(0.49)$ & 00 & 0 \\
Others & $01(0.16)$ & $01(0.16)$ & 00 & $01(0.16)$ \\
\hline
\end{tabular}

CT: Catheter tip, ET: Endotracheal tube, MRSA: Methicillin-resistant Staphylococcus aureus
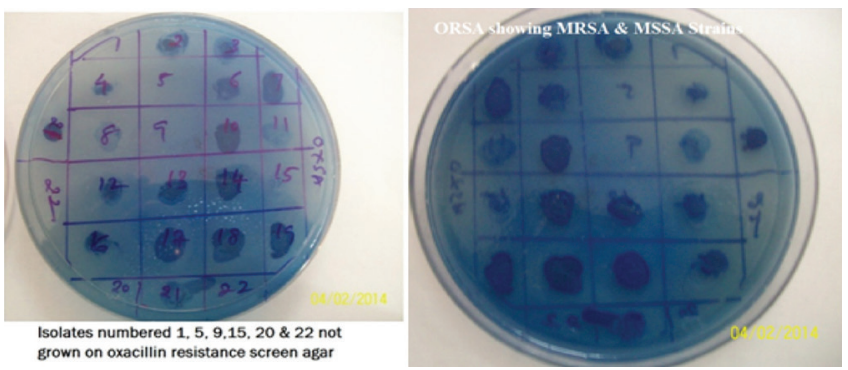

Fig. 3: (a and b) Oxacillin resistance screening of Staphylococcus aureus isolates. Methicillin-resistant $S$. aureus strains appeared blue colored on oxacillin-resistant screen agar. Blocks without growth represent methicillin-sensitive $S$. aureus isolates

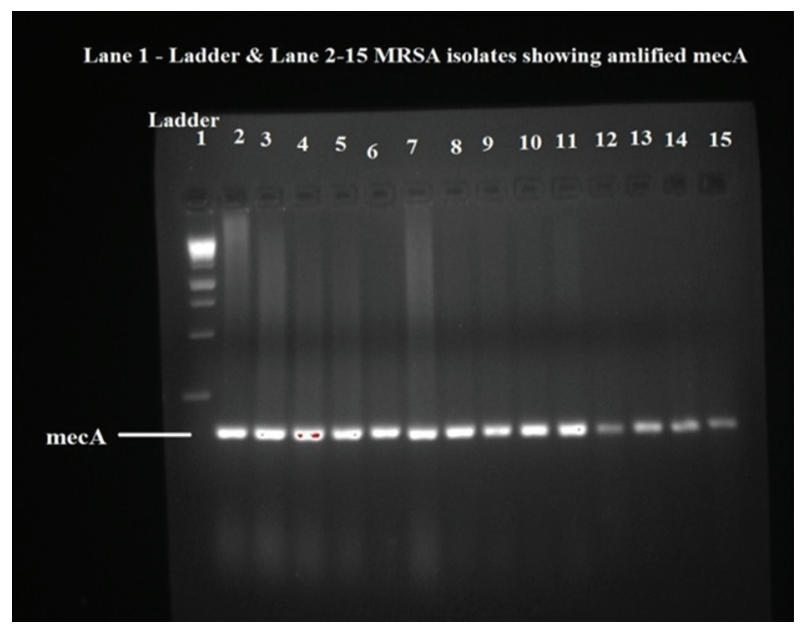

Fig. 4: Amplification of mecA locus. lane 1 is ladder and lanes 2-15 are methicillin-resistant Staphylococcus aureus isolates

\section{DISCUSSION}

Antimicrobial resistance is a worldwide problem, particularly among pathogens related to hospital-acquired infections. Staphylococci have become one of the most common causes of both hospital- and community-acquired infections [16-18]. The increased frequency of Staphylococcal infections along with the augmented problem of antimicrobial resistance has led to renewed interest in clindamycin usage [19]. Clindamycin is a good alternative drug for the treatment of skin, soft tissue, and bone infections because of its tolerability, oral bioavailability, accumulation in abscesses, and cost-effectiveness [3]. There has been a number of reported clindamycin therapy failure in Staphylococcal infections due to inducible resistance phenotype [19].

In accordance with the previous studies, we also observed $36.42 \%$ prevalence of MRSA among $S$. aureus infections as this was detected by

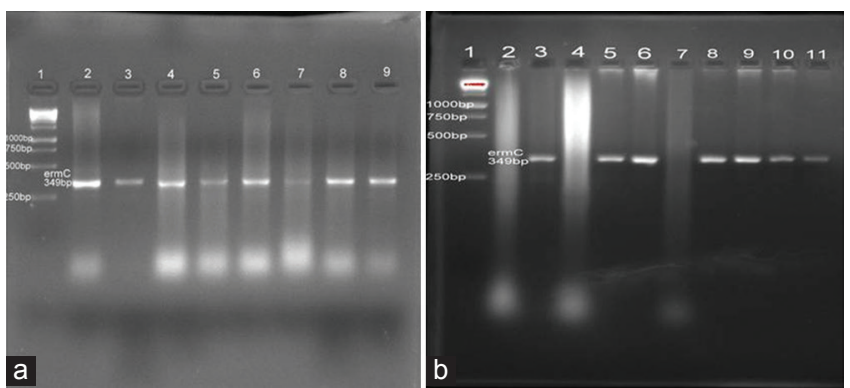

Fig. 5: (a) Amplification of ermC, Lane 1 - Marker, Lanes 2-7 test strains, Lane 8 - positive control. Gel doc showing separation, Lane 2-7 isolates are ermC positive and Lane - 8 positive strain as a control for PCR. (b) Amplification of ermC, Lane 1 - Marker, Lane 2-10 test strains, Lane 11 - positive control. Gel doc showing separation, Lane $-3,5,6,8,9,10$, and 11 isolates are ermC positive and Lane 11 standard strain as control for PCR

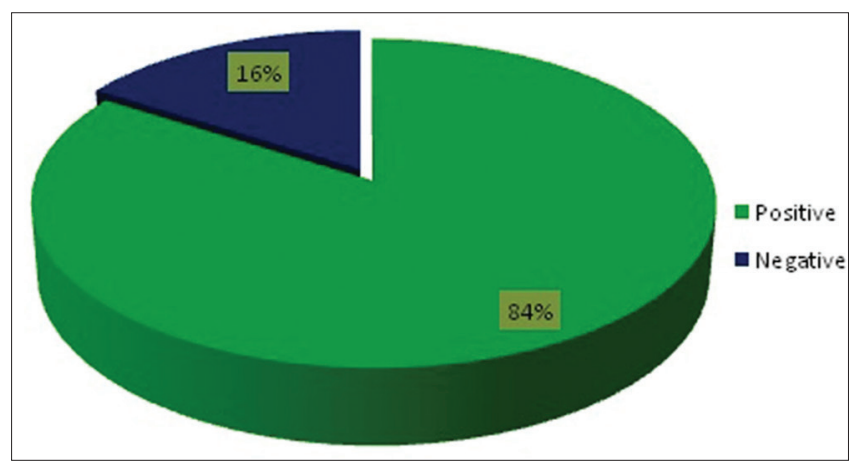

Fig. 6: Result of ermC gene detection by PCR

cefoxitin (D-test). In 2003, Anupurba et al. reported 54.82\% prevalence, and in another study conducted by Joshi et al. in 2013 [4], 42\% MRSA was detected among $S$. aureus infections $[4,20]$. This difference could be due to the prevalence of inducible clindamycin which may vary by geographic regions and even in different hospital setup [3].

In the current study, the majority of the MRSA isolates were observed from the department of surgery (21.68\%) followed by ICU $(11.75 \%)$ which may be because surgical interventions were needed in most of the cases. In a study conducted by Adam et al. in 2009 and Valsesia et al. in $2010,35 \%$ of cases were from the surgical ward and $86 \%$ of MRSA were commonly isolated from skin and soft tissue infections [21,22]. In another study, it was reported that skin and soft tissue infections as most commonly reported cases in emergency wards and MRSA were the most common strains isolated from abscesses (61\%), wounds (53\%), and cellulitis with purulent exudate (47\%) [23]. Concurrent with the previous study, the majority of the cases were from surgical wards and also MRSA was commonly isolated from skin and soft tissue infections. 
Among ermA, ermB, and erm $\mathrm{C}$ genes by $\mathrm{PCR}$, erm $\mathrm{C}$ is the predominant genetic determinant for the expression of resistance to macrolides among MRSA. In a previous study, of 1477 S. aureus isolates, 173 expressed resistance to erythromycin, constitutive phenotypes in 106 isolates, the inducible phenotype in 53, and MS phenotype in 13 cases. Most of the MRSA isolates carried the ermC gene followed by ermA gene and the $m s r$ [24]

Similarly, among 285 S. aureus isolates, inducible resistance was found in 38 (13.33\%) [25]. In another similar study, of 288 Staphylococcal isolates, $116(40.27 \%)$ were found to be MRSA resistant to cefoxitin. D-test was performed and showed erythromycin resistant and clindamycin sensitive in $21(18.1 \%)$ indicating inducible clindamycin resistances [3]. Concurrently, we reported that, among 604 S. aureus isolates, 220 (36.42\%) were of MRSA. Among them, 69 (11.42\%) were demonstrated as inducible clindamycin resistance.

In accordance to the previous report, we also observed 69 (11.42\%) isolates for MRSA + IR demonstrated by double-disk diffusion method phenotypically, whereas, 25 isolates were analyzed for the presence of ermA, B, and C genes. Of these, 21 (84\%) were observed to be as ermC positive by PCR. In a previous study, among 414 S. aureus isolates, 150 were MRSA of which $35.33 \%$ were demonstrated as inducible clindamycin resistant, and of 264 MSSA, $7.95 \%$ were inducible clindamycin resistant [26]. In another study, 55 MRSA isolates showed that there was no discordance between conventional susceptibility testing by Kirby-Bauer disk diffusion method and gene detection by multiplex PCR assay. The study showed the prevalence of erm(A) and $\operatorname{erm}(\mathrm{C})$ genes at the rate of $30.9 \%$ and $74.5 \%$, respectively [27].

\section{CONCLUSION}

We concluded that MRSA can be demonstrated by double disc diffusion method which is an appropriate treatment for the patients whenever clindamycin is to be used for S. aureus infections. Among ermA, ermB, and erm $\mathrm{C}$ genes, ermC is the predominant genetic determinant for the expression of resistance to macrolides among MRSA. We recommend that the isolates which are erythromycin resistant and clindamycin sensitive should be checked phenotypically for inducible resistance by D-zone test and genotypically for the presence of erm gene.

\section{CONFLICTS OF INTEREST}

The authors have no conflicts of interest.

\section{AUTHOR'S CONTRIBUTION}

All the authors have substantially contributed in the research and publication of this study.

\section{REFERENCES}

1. Kapil A. Textbook of Microbiology. $9^{\text {th }}$ ed. India: Universities Press; 2013.

2. Molton JS, Tambyah PA, Ang PS, Ling LM, Fisher AD. The global spread of healthcare-associated multidrug-resistant bacteria: A perspective from Asia. Clin Infect Dis 2013;56:1310-8.

3. Jindal N, Singh S, Grover P, Malhotra R. Prevalence of inducible clindamycin resistance among clinical isolates of MRSA in Malwa region of Punjab (North India), PARIPEX. Indian J Res 2013;10:133-4.

4. Joshi S, Ray P, Manchanda V, Bajaj J, Chitnis SD, Vikas G, et al. Methicillin resistant Staphylococcus aureus (MRSA) in India: Prevalence and susceptibility pattern. Indian J Med Res 2013;137:363-9.

5. Available from: http://www.who.int/gpsc/country_work/gpsc_ccisc_ fact_sheet_en.pdf. [Last accessed on 2017 Sep 25].

6. Kock R, Becker K, Cookson B, Van Gemert-Pijnen JE, Harbarth S, Kluytmans J, et al. Methicillin-resistant Staphylococcus aureus (MRSA): Burden of disease and control challenges in Europe. Eurosurveillance 2010;15:19688.

7. Filice AG, Nyman AJ, Lexau C, Lees HC, Bockstedt AL, Lindsay A, et al. Excess costs and utilization associated with methicillin resistance for patients with Staphylococcus aureus infection. Infect Control Hosp Epidemiol 2010;31:365-73.

8. Ellingson K, Muder RR, Jain R, Kleinbaum D, Feng IJ, Cunningham C, et al. Sustained reduction in the clinical incidence of methicillin resistant staphylococcus aureus colonization or infection associated with a multifaceted infection control intervention. Infect Control Hosp Epidemiol 2011:32:1-8.

9. Albiger B, Griskeviciene J, Heuer O, Hogberg DL, Suetens C. Annual Epidemiological Report, Reporting on 2011 Surveillance Data and 2012 Epidemic Intelligence Data; 2013. p. 199-205.

10. Gupta KY, Gupta G, Bishnoi RB, Binnani A, Garg PS. Phenotypic detection of inducible clindamycin resistance in Staphylococcus aureus. IJPRBS 2013;2:267-72.

11. Forrest GN, Oldach DW. Macrolides and clindamycin. In: Gorbach SL, Barlett JG, Blacklow NR, editors. Infectious Diseases. $3^{\text {rd }}$ ed. Philadelphia, PA: Lippincott Williams and Wilkins; 2004. p. 223.

12. Zelazny MA, Ferraro JM, Glennen A, Hindler FJ, Mann ML, Munro S, et al. Selection of strains for quality assessment of the disk induction method for detection of inducible clindamycin resistance in staphylococci: A CLSI collaborative study. J Clin Microbiol 2005;43:2613-5.

13. Chelae S, Laohaprertthisarn V, Phengmak M, Kongmuang U, Kalnauwakul S. Detection of inducible clindamycin resistance in staphylococci by disk diffusion induction test. J Med Assoc Thai 2009;92:947-51.

14. Fiebelkorn KR, Crawford SA, McElmeel ML, Jorgensen JH. Practical disk diffusion method for detection of inducible clindamycin resistance in Staphylococcus aureus and coagulase-negative staphylococci. J Clin Microbiol 2003;41:4740-4

15. Lina G, Quaglia A, Reverdy EM, Leclercq R, Vandenesch F, Etienne J. Distribution of genes encoding resistance to macrolides, lincosamides, and streptogramins among staphylococci. Antimicrob Agents Chemother 1999;43:1062-6.

16. Nashwa M, Al-Kasaby MN, El-Khier AT. Phenotypic and genotypic detection of MLS resistance among clinical isolates of Staphylococcus aureus from Mansoura University: Children Hospital, Egypt. Afr J Microbiol Res 2017;11:488-94.

17. Divyashanthi CM, Adithiyakumar S, Bharathi N. Study of prevalence and antimicrobial susceptibility pattern of bacterial isolates in a tertiary care hospital. Int J Pharm Pharm Sci 2015;7:185-90.

18. Vanitha RN, Gopal K, Narendra MV, Vishwakanth D, Nagesh VR, Yogita $\mathrm{M}$, et al. A retrospective study on blood stream infections and antibiotic susceptibility patterns in a tertiary care teaching hospital. Int J Pharm Pharm Sci 2012;4:543-8.

19. Fasih N, Irfan S, Zafar A, Khan E, Hasan R. Inducible clindamycin resistance due to expression of erm genes in Staphylococcus aureus. Report from a tertiary care hospital Karachi, Pakistan. J Pak Med Assoc 2010;60:750-3.

20. Anupurba S, Sen MR, Nath G, Sharma BM, Gulati AK, Mohapatra TM. Prevalence of methicillin resistant Staphylococcus aureus in a tertiary referral hospital in eastern Uttar Pradesh. Indian J Med Microbiol 2003;21:49-51.

21. Adam JH, Allen GV, Currie A, McGeer JA, Simor EA, Richardson ES, et al. Community-associated methicillin resistant Staphylococcus aureus: Prevalence in skin and soft tissue infections at emergency departments in the Greater Toronto Area and associated risk factors. CJEM 2009;11:439-46.

22. Valsesia G, Rossi M, Bertschy S, Pfyffer EG. Emergence of sccmec type IV and sccmec Type V Methicillin resistant Staphylococcus aureus containing the panton-valentine leukocidin genesina large academic teaching hospital in Central Switzerland: External invaders or persisting circulators? J Clin Microbiol 2010;48:720-7.

23. Moran GJ, Krishnadasan A, Gorwitz RJ, Fosheim GE, McDougal LK, Carey RB, et al. Methicillin resistant Staphylococcus aureus infections among patients in the emergency department. N Engl J Med 2006;355:666-74.

24. Spiliopoulou I, Petinaki E, Papandreou P, Dimitracopoulos G. erm(C) is the predominant genetic determinant for the expression of resistance to macrolide among methicillin resistance Staphylococcus aureus clinical isolates in Greece. J Antimicrob Chemother 2004;53:814-7.

25. Vidhya R, Parimala S, Beena PM. Inducible clindamycin resistance in Staphylococcus aureus isolates from a rural tertiary care hospital, Kolar. J Clin Biomed Sci 2013;3:125-8

26. Upadhya A, Biradar S. Prevalence of inducible clindamycin resistance in Staphylococcus aureus in a tertiary care hospital in north-east Karnataka, India. Health Sci Int J 2011;1:21-4.

27. Adwan G, Adwan K, Jarrar N, Amleh A. Molecular detection of nine antibiotic resistance genes in methicillin resistant Staphylococcus aureus isolates. Roum Arch Microbiol Immunol 2014;73:9-17. 